\title{
A quality framework for health services developed through an inclusive approach
}

\author{
Trish Markham ${ }^{* 1}$, Michelle Butler ${ }^{2}$, Martin McNamara ${ }^{3}$ \\ ${ }^{1}$ HSE, Millenium Park, Naas, Co.Kildare, Ireland \\ ${ }^{2}$ Department of Family Practice, University of British Columbia, Vancouver, Canada \\ ${ }^{3}$ University College Dublin, Belfield, Dublin, Ireland
}

Received: January 5, 2015

DOI: $10.5430 /$ jnep.v5n5p110
Accepted: February 26, 2015 Online Published: March 18, 2015

URL: http://dx.doi.org/10.5430/jnep.v5n5p110

\begin{abstract}
Objective: This study set out to explore and define the concept of "quality" from the perspective of health service managers and health professionals in Ireland, and to develop a theory to inform the development of a quality framework for the Irish health system.

Methods: Design: The study design was based on Strauss and Corbin's (1990) grounded theory approach. This provided a method of social inquiry with the purpose of developing a theory through a systematic and rigorous approach to examine and advance emerging concepts. Setting and participants: Fifty health service managers and professionals employed by the Health Service Executive (HSE) in Ireland participated in this study. Interventions: In-depth interviews were used to explore with participants their experiences of quality in Irish health services, definitions of quality and the elements necessary for a quality framework. Main outcomes: This study produced a substantive theory that identified the need for a holistic approach to quality across three domains (the patient, workforce and organisation).

Results: The quality framework comprises an integrated set of domains, values, approaches, processes and enablers. Across the domains, the approaches and processes provide the mechanisms to achieve quality. These are supported by values (that promote quality) and a set of enablers (which underpin the elements, providing the platform for change).

Conclusions: The emergent theory provides the basis for a quality framework for health services for Ireland in the $21^{\text {st }}$ Century. Unlike most extant quality frameworks, the framework was derived empirically through an inclusive approach with key care providers, supporting the relevance and potential utility of the framework.
\end{abstract}

Key Words: Quality, Framework, Total quality improvement, Health services, Ireland

\section{INTRODUCTION}

Environments in which health systems operate have changed rapidly, exerting many pressures on systems worldwide. ${ }^{[1]}$ The issue of defining quality in the provision of health services is central to improving overall organisational effectiveness ${ }^{[2]}$ given the complex, multi-dimensional nature of the system, which incorporates different activities, views and stakeholders. Differing conceptualisations of quality can result in some elements of a system being prioritised over others, which in turn have implications for organisations overall. Total quality improvement means optimising the whole system, so that all areas operate to their potential. ${ }^{[3]}$ This requires promoting and embedding within the organisation a shared understanding of what quality means

\footnotetext{
*Correspondence: Trish Markham; Email: trish.markham@hse.ie; Address: National Business Manager, HSE, Millenium Park, Naas, Co.Kildare,
} Ireland. 
and a vision of how it can be achieved and supported by appropriate structures within the organisation. ${ }^{[4]}$

Different perspectives on health service quality exist in the literature, along with numerous definitions and descriptions of the concept. Some authors suggest quality ought to adopt a scientific dimension, specifically measurement, standard setting and improvement. ${ }^{[5]}$ Others consider quality to be the degree of excellence intended and the control of variables in achieving that excellence to meet customer need. ${ }^{[6]}$ The World Health Organisation (WHO) defines a quality health system as one that organises resources in the most effective way to meet the health needs of those most in need of care, safely and without waste. ${ }^{[7]}$ Once quality is defined, it is important to rationalise and operationalise the concept. ${ }^{[8]}$ Table 1 outlines a summary of the quality theories identified in the literature.

Table 1. Summary of theories about quality

\begin{tabular}{|c|c|c|c|}
\hline Author & Concept & Focus & Factors \\
\hline $\begin{array}{l}\text { Shewhart } \\
\text { (1939) }\end{array}$ & $\begin{array}{l}\text { Adapting processes to create } \\
\text { profitable situations }\end{array}$ & $\begin{array}{l}\text { The Shewhart Cycle } \\
\text { Plan, Do, Study and Act }\end{array}$ & $\begin{array}{l}\text { Constant evaluation } \\
\text { Enhance learning } \\
\text { Quality improvement }\end{array}$ \\
\hline $\begin{array}{l}\text { Crosby } \\
(1979)\end{array}$ & Conformance to requirements & $\begin{array}{l}\text { Consistently reproduce } \\
14 \text { steps to improvement }\end{array}$ & $\begin{array}{l}\text { Quality is free } \\
\text { Zero defects } \\
\text { Quality is a continuous process }\end{array}$ \\
\hline $\begin{array}{l}\text { Donadedian } \\
\text { (1988) }\end{array}$ & Structure, process, outcome & $\begin{array}{l}\text { Focuses on the systemisation of } \\
\text { knowledge in an organisation }\end{array}$ & $\begin{array}{l}\text { Variables such as facilities, } \\
\text { equipment, human resources and } \\
\text { leadership are components in } \\
\text { achieving quality }\end{array}$ \\
\hline Deming (1982) & Introduced Statistical Process & Systems improvement & Management has responsibility \\
\hline $\begin{array}{l}\text { Iskikawa } \\
\text { (1985) }\end{array}$ & $\begin{array}{l}\text { Development of Fishbone } \\
\text { Cause and Effect } \\
\text { Developed seven basics tools } \\
\text { for quality }\end{array}$ & $\begin{array}{l}\text { Involvement of top management } \\
\text { involvement } \\
\text { People to be happy } \\
\text { Organisational wide quality control }\end{array}$ & $\begin{array}{l}\text { Search for causal factors } \\
\text { systematically - represents analysis } \\
\text { of the real cause behind problem } \\
\text { Planning cycle for process } \\
\text { improvement }\end{array}$ \\
\hline $\begin{array}{l}\text { Juran } \\
(1951)\end{array}$ & $\begin{array}{l}\text { Fitness for use } \\
\text { Output / Product }\end{array}$ & Able to count on service or product & $\begin{array}{l}\text { Managerial breakthrough sequence } \\
\text { List of steps to produce quality }\end{array}$ \\
\hline $\begin{array}{l}\text { Taguchi } \\
\text { (1993) } \\
(1999)\end{array}$ & $\begin{array}{l}\text { Robust design in the } \\
\text { manufacturing process, rather } \\
\text { than attempt to control the } \\
\text { variances }\end{array}$ & $\begin{array}{l}\text { Three stages: } \\
\text { System design } \\
\text { Parameter design } \\
\text { Tolerance design }\end{array}$ & $\begin{array}{l}\text { Robust design, resistant to } \\
\text { variation, not quality through } \\
\text { inspection }\end{array}$ \\
\hline $\begin{array}{l}\text { Berwick } \\
\text { (1989) }\end{array}$ & $\begin{array}{l}\text { Access, knowledge and the } \\
\text { interaction between these two }\end{array}$ & Patient centeredness & Transparency and accountability \\
\hline $\begin{array}{l}\text { Shortell } \\
\text { (1973) }\end{array}$ & $\begin{array}{l}\text { Managers play a role. } \\
\text { Identify high level priorities }\end{array}$ & $\begin{array}{l}\text { Integrated health system that } \\
\text { minimises fragmentation }\end{array}$ & $\begin{array}{l}\text { Accountability } \\
\text { Alignment of systems, teams and } \\
\text { structures }\end{array}$ \\
\hline
\end{tabular}

Similar to many health systems, the Irish health system faces a number of challenges such as the complexity of organisational structures, dealing with new and emerging strategic and operational issues, rapid change, and limited financial resources. ${ }^{[9]}$ It has been subject to a number of reforms in recent decades, many emanating from a national health strategy published in 1994. ${ }^{[10]}$ Amidst the waves of radical reform is the explicit commitment to deliver quality health services, ${ }^{[5,8,10]}$ including the establishment of the Health Information and Quality Authority (HIQA) in 2007, which aimed to strengthen governance and accountability across the health system by setting and monitoring standards. ${ }^{[11]}$ There is scope for improvement in every organisation. ${ }^{[12]}$ To achieve this, systematic and self-conscious management is needed for improvements to occur in the quality of health services. $^{[13]}$ The responsibility for developing a working environment capable of supporting quality lies with the organisation itself and in turn with the personnel within it. ${ }^{[14]}$ It is important to address the factors that impact on an organisation's ability to deliver quality services. ${ }^{[15]}$ Where clear strategic direction exists, employees are motivated to perform at higher levels, enhancing the performance of the organisa- 
tion overall. ${ }^{[16,17]}$ Such strategic direction can be provided through the development of an explicit framework for quality, that promotes the vertical and horizontal alignment required for policy development and system changes. ${ }^{[18]}$ A structure has been called for to provide a strategic, unified approach to support quality in the Irish health system. ${ }^{[19]}$ This study set out to address this deficit by developing a theory about quality that could inform the development of a quality framework. The research approach was deliberately inclusive, to ensure the relevance and fit of the emerging framework to the requirements of the Irish health system.

\section{METHOD}

A grounded theory design, based on Strauss and Corbin's approach $^{[20]}$ was used to construct a theory to inform the development of a quality framework. The approach aimed to examine the concept of quality from the perspective of those involved in health service delivery and management and to use this data to construct a theory that represents participants' views and experiences. Ethical approval for the study was obtained from the University College Dublin Ethics Committee, Dublin, Ireland (Ref No: LS-09-42).

\subsection{Sample}

Purposive sampling was initially used to select participants who could contribute to the topic under exploration on the basis of their role within the Irish health system, and their knowledge, experience, or particular perspectives on quality. Professionals and managers were sought from a range of disciplines at a variety of levels of seniority. As the theory began to develop, theoretical sampling occurred whereby informants were identified who could build on and add to the emerging theory. ${ }^{[21]}$ Sampling continued until a broad range of perspectives on quality was examined - maximising sample variation, and no new data were identified - indicating that data saturation was achieved. This resulted in a sample of 50 participants. Participants were provided with detailed written information and were asked to provide written consent before being interviewed.

\subsection{Data collection}

Data were collected through in-depth semi-structured interviews, providing the flexibility to follow up emerging ideas and to seek further clarification around understandings and experiences of quality. ${ }^{[22]}$ A topic guide was constructed to assist in prompting and probing for information. Some questions initially explored included:

- What do you consider constitutes quality healthcare?

- How would you define quality?

- Can you recall an incident in which you feel a quality service was provided?
- Can you recall an incident where you could not provide a quality service?

- What would assist in the delivery of a quality healthcare service?

- What processes could be developed to support quality?

- If you could change any aspect of your role in relation to delivering quality, what would it be?

- What are the essential elements required to develop a Quality framework?

The focus of questions evolved over the course of the study to incorporate new themes as they emerged from data analysis. Interviews were transcribed verbatim and coding commenced immediately afterwards.

\subsection{Data analysis}

An essential element of grounded theory is that data collection and data analysis occur simultaneously. The constant comparative method ${ }^{[20]}$ involved constantly comparing each piece of data being collected with existing data to generate meaning. As the theory emerged, it informed subsequent data collection. The aim of data analysis was to discover core concepts to provide a foundation for theory generation. The process began with open coding of each transcript separately to identify themes contained within the data. Next, codes were compared and similar codes were clustered to begin to form a category (axial coding). By comparing similar and deviant incidents within categories, the basic properties and dimensions of the categories began to emerge. Further comparisons and analysis of categories and their interrelationships led to the emergence of theoretical constructs, while hypotheses that emerged were tested to verify various categories and constructs. Interrelated and multifaceted connections and relationships were identified and validated during analysis in terms of causal conditions, context, intervening conditions, actions, interactions, strategies and consequences (selective coding).

Field notes and memos were maintained throughout the analysis process. The software package Nvivo (V9) ${ }^{[23]}$ was used to organise, sort, retrieve and compare data during open, axial and selective coding. A template was designed to summarise the key findings at different levels of coding in each category. Data collection continued until no new information/themes were identified, indicating that theoretical saturation had been achieved. ${ }^{[24]}$

\section{RESULTS}

Participants were from a range of backgrounds, work experiences and years of service (see Table 2). 


\subsection{Defining quality}

Interviews began by exploring participants' understandings of quality. Several participants found it difficult to define quality as a concept and different ideas were identified in the data, suggesting the lack of a coherent vision for quality amongst participants.

I'm not sure how I would define quality. (P47)

Quality is an area that people don't understand in the health service. (P11)

Quality was depicted as a complex, multi-dimensional and relational concept, incorporating a number of essential components working together towards the achievement of the best possible outcomes.

Quality within the health services has probably a couple of remits... the patient, the staff and the organisation. (P27)

I think quality encapsulates a whole range of issues... in terms of the way we organise our services...co-ordinate efforts... rationalising approaches. (P15)

A quality service is delivering competent, safe, efficient, cost-effective services that achieve its objectives. (P8)

...the best possible result for each outcome... for every situation. (P44)

Common themes identified within the data were progressively distilled to produce an overarching definition of quality in the health service context: The pursuit of the best possible outcomes within available resources.

Participants supported the need for an overarching framework for the health system that would provide a clear vision and a unity of purpose for all involved in the pursuit and achievement of quality.

An actual framework, you have to have your vision and what you want to achieve and it has to be deliverable. It would focus objectives for people, so they have some thing to work towards. (P3)

3.2 The substantive theory of quality for Irish health services

The substantive theory that emerged in this study identifies three key components for a quality framework: domains, elements and enablers (see Figure 1). The domains represent three separate but linked dimensions of quality: the patient, the workforce and the organisation. These domains are supported by elements: approaches and processes, supported by values. These elements are the mechanisms to achieve quality. A set of enablers underpins these integrated elements, providing the platform for change and system improvements.

Table 2. Characteristics of participants

\begin{tabular}{lll}
\hline Characteristic & n & \% \\
\hline Pillar & 33 & $(67)$ \\
Management & 12 & $(25)$ \\
Medical & 5 & $(8)$ \\
Nursing & & \\
Gender & 13 & $(27)$ \\
Male & 37 & $(73)$ \\
Female & & \\
Area of work within the health service & & $(20)$ \\
Primary Community Continuous Care & 10 & $(22)$ \\
Corporate & 11 & $(30)$ \\
Population Health & 15 & $(6)$ \\
Human Resources & 3 & $(4)$ \\
Communications & 2 & $(8)$ \\
Finance & 4 & $(10)$ \\
National Hospitals Office & 5 & \\
Years experience in the health service & & $(6)$ \\
0-5 Years & 3 & $(28)$ \\
5-10 Years & 14 & $(32)$ \\
10-20 Years & 16 & $(16)$ \\
20-30 Years & 8 & $(18)$ \\
30-40 Years & 9 & \\
\hline & & \\
& &
\end{tabular}

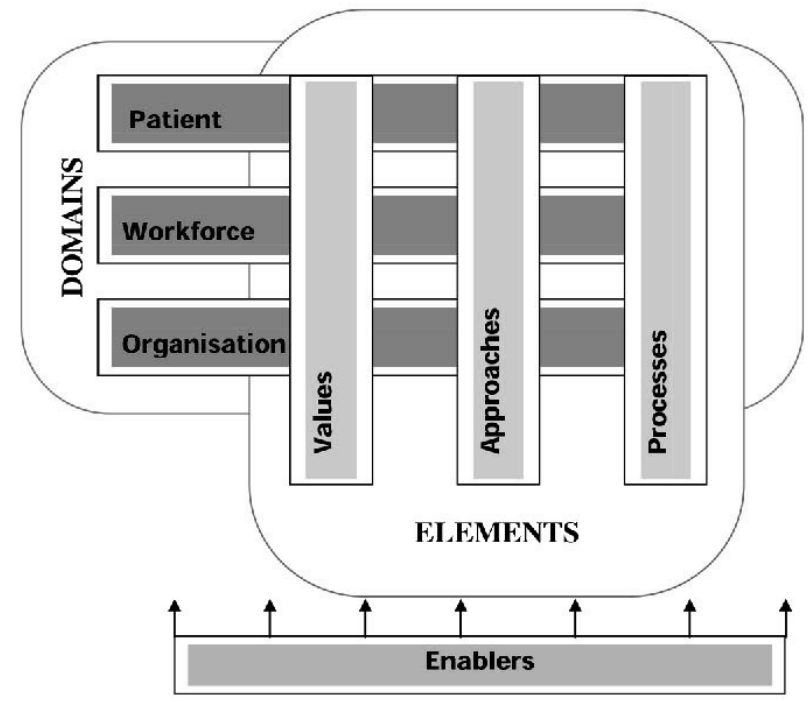

Figure 1. The substantive theory of quality

\subsection{Values}

Five values support the organisation in delivering quality healthcare. In defining quality, participants referred to the need for health services that are focused on the patients' 
needs.

Quality health services... have to be patientfocused so that service delivered focuses on improving services. (P29)

Emphasis was placed on the importance of services being accessible and equitable for the patient.

It is about the users and easy access, so that services are clearly understood by the users. (P23)

The importance of decisions being evidence-based emerged as essential to quality in the health service.

I would define quality as a service that is evidence-based. (P30)

Participants also highlighted the importance of having a skilled and capable workforce and the continuous development of people capacity.

You need people on the ground who know how to manage, who know how to be clinicians and to get that balance. $(\mathrm{P} 16)$

Lastly, effective resource management was identified as a key component to the delivery of effective and efficient services.

A quality health service is one that is efficient and by that I mean that money and peoples time are used properly to get the best outcomes for patients and the health service. (P49)

These values were considered the basis for continuous quality improvement and change within the health system.

\subsection{Approaches}

Three approaches were identified to support the achievement of quality: risk management, planning and corporate governance. These reflect activities that were considered necessary to support quality outcomes.

The quality of care provided in hospitals and communities evolves around and is based on patient safety. (P3)

The approaches were envisioned as planned, systematic mechanisms to guide system choices and support organisational change.

Good planning is very important. There is a lot more awareness in relation to quality, value for money and better outputs. (P5)
The health service needs a governance structure so that there is a clear set of rules which have to be abided by. I think that it supports professionalism and lets people know what is expected from them. (P50)

Emphasis was placed on approaches being an integral part of everyday health service business.

\subsection{Processes}

Four processes were identified: consultation, education and training, standard setting and audit. These were reflected in a systematic series of actions and steps that lead to achieving quality outputs.

Quality...can be achieved by having proper processes in place on where we want to get to and how we propose to get there. (P42)

Processes were considered to be supportive of quality improvements and necessary to achieve organisational reform. It was suggested that processes are reliant on organisational ability.

It is important to look at and audit the quality improvements that we put in place, to see if we were reaching the targets or not. (P28)

Processes were described as assisting and co-ordinating the redesign of organisational workflows to achieve set standards and quality outputs.

The interaction between clients and the health care providers at every level is hugely enhanced if there is an exchange of information. (P23)

\subsection{Enablers}

Four enablers were identified to support the different components of the framework. These included: clear structures, information management, communication and change management.

A good quality health service includes a good clear vision and mission. . . good clear work practices... If there is clear structures, everyone is clear, good communications exists... things would be unified and more effective...this would be very beneficial. (P4)

The enablers were considered to reflect the means and mechanisms to support the achievement of quality. Information management was considered vital to the development of health services in achieving quality.

ISSN 1925-4040 E-ISSN 1925-4059 
Quality systems, access to information systems to support knowledge management and communication... supports sharing information. (P27)

Communication was described as necessary to promote knowledge and information sharing whilst supporting effective change management.

You can have quality around integration, quality issues around the treatment provided and what the outcomes are... Ultimately, you need the ability to change to achieve pre-determine targets. (P18)

\subsection{The quality framework}

The detail in the substantive theory was used to inform and create a visual diagram to conceptualise a quality framework for the Irish health system. The construct attempted to depict the inter-connections and overlap required to support quality. The framework was further developed by deconstructing the components (categories) into clear, manageable parts (dimensions and properties). This aimed to support understanding of the framework and adds an aspect not documented in the literature previously. It has the ability to act as a guide in operationalising the framework. Figure 2 outlines the composition of the quality framework developed in this research.

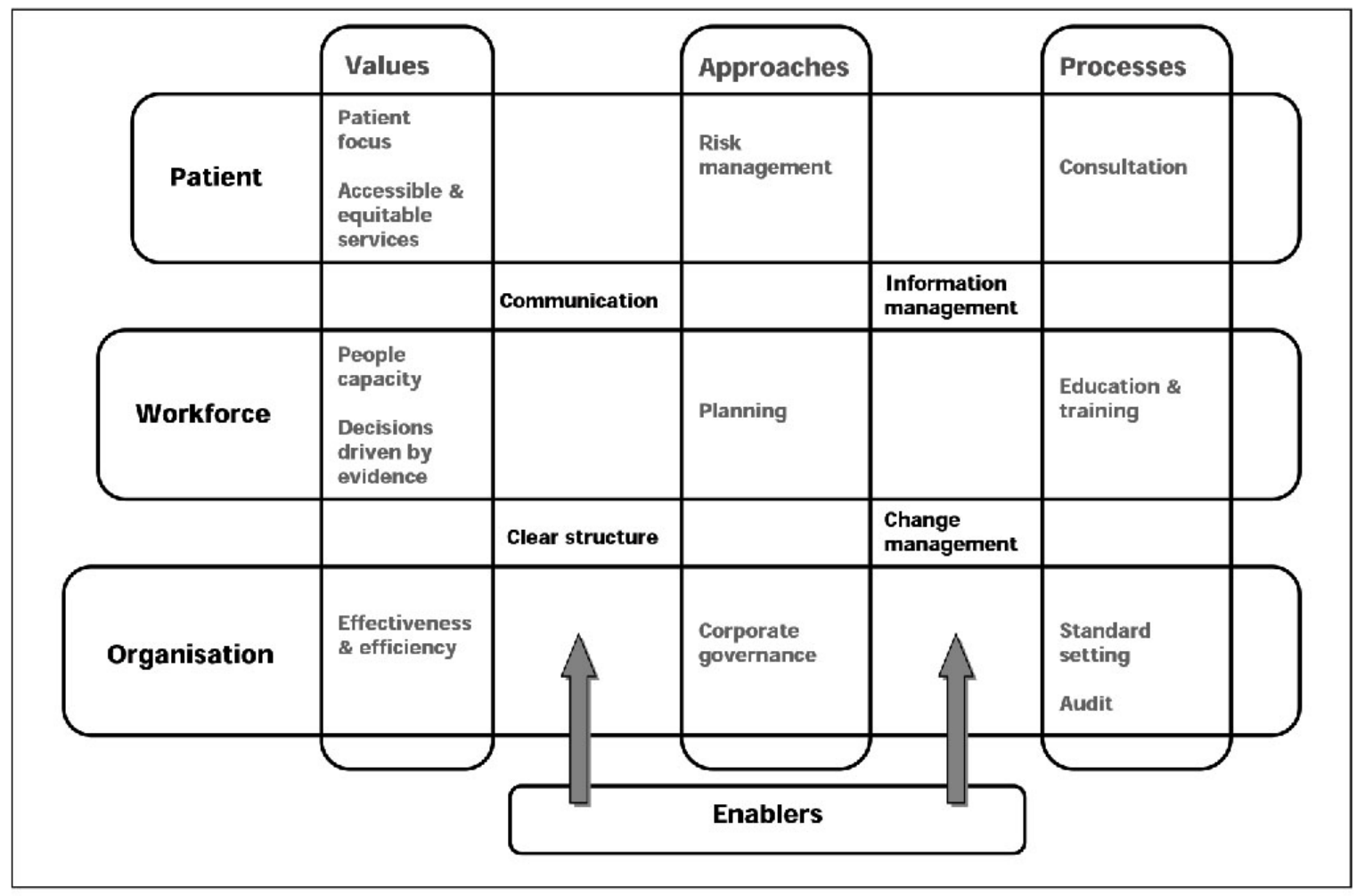

Figure 2. A quality framework for the Irish health service

\section{Discussion}

Unlike most extant quality frameworks, the theory in this research was derived through an inclusive approach with key care providers. As such the theory is likely to be relevant to those involved in planning and delivering health care in Ireland and those initiating and managing change in the Irish health system.

Organisations are described as social systems comprising a set of components, ${ }^{[25]}$ that involve a series of connected functions and activities to achieve outcomes ${ }^{[26]}$ that work together ${ }^{[27]}$ and influence each other. ${ }^{[28]}$ A system's perfor- mance depends on how well the parts fit together, not how well they perform individually. ${ }^{[29,30]}$ The emergent theory in this study supports this finding, as the theory implies that the collaborative integration of the components and the interaction between them is the best means to achieve the best outcome in terms of quality. It also provides a basis for change when we consider healthcare organisations to be complex adaptive system $\mathrm{s}^{[31,32]}$ where rather than imposing prescriptive rules, change is best achieved by identifying and working with the values and behaviours that people are drawn towards and the use of minimum specifications or principles for action through which change in a specified 
direction is encouraged.

The framework, as a single blueprint for change promotes a shared understanding of quality and how it can be achieved, for the entire organisation. ${ }^{[33,34]}$ Understanding quality in health services is difficult, which impinges on the ability to support it. ${ }^{[35]}$ The framework in this study provides a holistic approach and includes a range of multi-dimensional, interrelated components, whereas a framework that is unduly narrow and clinically focused may overlook other key organisational areas. The increasing recognition of using a broader framework is noted in the literature. ${ }^{[36,37]}$

A framework enables the breakdown and integration of multiple facets with each corresponding to a health system function $^{[38]}$ e.g., planning activities in a health service. These facets become the structures on which progresses are built. ${ }^{\text {[39] }}$ When developing a quality framework, it is important to build on the knowledge and systems already in place. ${ }^{[40]}$ The function of the framework in this study is to promote the achievement of the highest standards, delivering evidencebased services, setting clear targets, monitoring, measuring against performance, undertaking audits and encouraging engagement in governance activities to achieve accountability in the organisation. Policy makers and managers need to work through decision-making processes and consciously determine areas for reform and improvement that are evidencebased. Issues such as accessibility and equity are dimensions that are system-dependent and cannot be improved without reforming the broader health service system. ${ }^{[41]}$ This study captured the intrinsically linked, interdependent components that collectively and systematically support the achievement of organisational improvements. The framework in this study is a holistic, integrated illustration of what quality means and how it can be represented in a health service.

\section{Conclusion}

The theory of quality in this study builds on what is already known and provides new insights to the understandings of quality across the heath system. The theory represents a comprehensive and holistic view of quality, identifying key components and dimensions of quality and the linkages between them. Together they provide the basis for a quality framework that can be used to guide and support change across the Irish health system towards the achievement of the best outcomes within available resources.

\section{ACKNOWLEDGEMENTS}

Michelle Butler and Martin McNamara contributed in the planning and reporting stages of this research. They provided assistance in the study design including the interpretation and presentation of the data.

\section{CONFlicts OF INTEREST Disclosure}

The authors declare that there is no conflict of interest statement.

\section{REFERENCES}

[1] Armitage GA, Suter D, Oelke ND, et al. Health systems integration: state of the evidence International Journal of Integrated Care. 2009; 11: 1841-1849.

[2] Meads G, Wild A, Griffiths F, et al. The management of new primary care organisations: an international perspective. Health Services Management Research. 2006; 19: 166-173. PMid:16848957 http://dx.doi.org/10.1258/095148406777888125

[3] Sterns JB. Quality Efficiency and organisational structure. Journal of Health Care Finance. 2007; 34: 100-107. PMid:18972989

[4] Kotter JP. Why Transformation Efforts Fail. Harvard Business Review. 2007; 1: 2-10.

[5] Ellis S. A concept analysis on the process of empowerment. Advances in Nursing Science. 1998; 21: 62-68. http://dx.doi.org /10.1097/00012272-199812000-00007

[6] Marr H, Giebing H. Quality Assurance in Nursing. Concepts, methods and care studies. Campion Press Ltd. Edinburgh, 1994.

[7] World Health Organisation. Guidance on developing and safety strategies with a health system approach. WHO. Copenhagen, 2008.

[8] Western S. What do we mean by Organisational Development. Krakow: Advisio Press. Ontario, 2010.

[9] Collins C.G. Joyce J. Focus on quality in healthcare in Ireland. International Journal of Health Care. Quality Assurance. 2008; 21:
219-228. PMid:18578205 http://dx.doi.org/10.1108/09526 860810859067

[10] Department of Health. Shaping a healthier future: a strategy for effective healthcare in the 1990s. Stationery Office. Dublin. Ireland, 1994.

[11] Department of Health \& Children. Health Act 2007. The Stationery Office. Dublin. Ireland, 2007.

[12] Hall R. The strategic analysis of intangible resources. Strategic Management Journal. 2006; 13: 135-144. http://dx . doi .org/10.10 $02 / \mathrm{smj} .4250130205$

[13] Hastings Center Report. The place of quality improvements in Health Care. The ethics of using methods to Improve Health Care Quality and Safety. Special Report. July/August, 2006.

[14] Kunkel S, Rosenqvist U, Westerling R. The structure of quality systems is important to the process and outcome, an empirical study of 386 hospitals in Sweden. BMT Health Services Research. 2007; 104: 1-10.

[15] Harvey N. The Challenge of Supervisory Management. 2nd Edition. Oak Tree Dublin. Ireland, 2000.

[16] Wong A, Tjosvold D, Zhang P. Developing relationships in strategic alliances: commitment to quality and cooperation interdependence. Industrial Marketing Management. 2005; 34: 722-731. http: //dx.doi.org/10.1016/j.indmarman. 2004.12.007 
[17] Ramseook-Munhurrun P, Lukea-Bhiwajee SD, Naidoo P. Service Quality in the Public Service. International Journal of Management and Marketing Research. 2010; 3: 37-50.

[18] Schalocl RL, Verdugo MA. Conceptual and Measurement Framework to Guide Policy Development and Systems Change. Journal of Policy and Practice in Intellectual Disabilities. 2012; 9: 63-72. http://dx.doi.org/10.1111/j.1741-1130.2012.00329.x

[19] Byrne M. Implementing Performance Management in the Irish Health Sector. The Health Care Manager. 2006; 25: 114-121. http://dx.doi.org/10.1097/00126450-200604000-00003

[20] Strauss A, Corbin J. Basics of Qualitative Research. Grounded theory Procedures and Techniques. Sage. California, 1990.

[21] Melia KM. Rediscovering Glaser. Qualitative Health Research. 1996; 3: 368-377. http://dx.doi.org/10.1177/104973239600600 305

[22] Patton MQ. Qualitative evaluation and research methods. (2nd ed.). Newbury Park. Sage Publications. London, 1990.

[23] QSR International (1999-2010) New software launched to harness data explosion for business and research. CFO World. Business Finance Leadership, 2010.

[24] Bringer JD, Halley JL, Brackenridge CH. Using Computer-Assisted Qualitative Data Analysis Software to Develop a Grounded Theory Project. Field Methods. Sage Publication. 2006; 18: 245-266. http://dx.doi.org/10.1177/1525822X06287602

[25] Bertalanffy VL. General systems theory. Foundation, Development, Applications. G. Braziller. New York, 1968.

[26] Mitchell M, Newman M. Complex systems theory and evolution. Encyclopedia of Evolution. Oxford University Press. New York, 2002.

[27] Deming WE. Quality, productivity and competition position. Massachusetts Institute of Technology, Cambridge, MA, 1988.

[28] Senge P. The Fifth Discipline: the Art and Practice of the Learning Organization. Doubleday. New York, 1990.

[29] Leischow SJ, Milstein B. Systems Thinking and Modeling for Public Health Practice. American Journal of Public Health. 2006; 96: 403405. PMid:16449572 http://dx.doi.org/10.2105/AJPH. 2005 .082842
[30] Plsek PE, Greenhalgh T. The challenge of complexity in health care. British Medical Journal. 2001; 323: 625-8. PMid:11557716 http://dx.doi.org/10.1136/bmj .323.7313.625

[31] Rowe A, Hogarth A. Use of complex adaptive systems metaphor to achieve professional and organizational change. Journal of Advanced Nursing. 2005; 51: 396-405. PMid:16086808 http://dx.doi.org /10.1111/j.1365-2648.2005.03510.x

[32] Clancy TR. Control: what we can learn from complex systems science. June. The Journal of Nursing Administration. 2008; 38: 272 274. PMid:18562830 http://dx.doi.org/10.1097/01.NNA.00 00312790.89879 .67

[33] Hansen MD. Management systems. Integrating safety, health, environments and quality programs. Professional Safety. 2006; 51: 34-41.

[34] Ibrahim AM, Sharp JM, Syntetos AA. A framework for the implementation of ERP to improve business performance: a case study. European and Mediterranean Conference on Information Systems. 2008; 2-10.

[35] Wren MA. Unhealthy State. New Island Press. Dublin. Ireland, 2003.

[36] World Health Organisation. The World Health Report-Working Together for Health. WHO. Copenhagen, 2006.

[37] Atun R, De Jongh T, Secci F, et al. Integration of targeted health interventions into health systems: a conceptual framework for analysis. Health Policy Plan. 2010; 25: 104-111. PMid:19917651 http://dx.doi.org/10.1093/heapol/czp055

[38] National Health Priority Action Council (NHPAC). National Chronic Disease Strategy. Australian Government Department of Health and Ageing. Canberra. Australia, 2006.

[39] Handler A, Issel M, Turnock B. A Conceptual Framework to Measure Performance of the Public Health System. American Journal of Public Health. 2001; 91: 1235-1239. http://dx.doi.org/10.21 05/AJPH.91.8.1235

[40] Lewisohn C, Reynoso J. Improving health service quality from within, the case of united Leeds teaching hospitals. NHS Trust. International Journal of Health care quality assurance. 1995; 8: 18 20. PMid:10142012 http://dx.doi.org/10.1108/095268695 10081848

[41] Ovretveit J. Total Quality Management in European healthcare. International Journal of healthcare quality assurance. 2000; 13: 74-80. http://dx.doi.org/10.1108/09526860010319523 